\title{
Interactions between tram passengers and road vehicles at tram stops - a pilot study
}

\author{
Piotr Soczówka $a^{a}$ Renata Żochowska \\ ${ }^{a}$ Silesian University of Technology, Faculty of Transport and Aviation Engineering, Department of Transport Systems \\ and Traffic Engineering, Krasińskiego 8, 40-019 Katowice, Poland, e-mail: piotr.soczowka@polsl.pl
}

ABSTRACT: Modern urban and metropolitan areas face numerous problems associated with transport activity, such as pollution, congestion, noise or traffic incidents. One of the solutions to cope with these issues may be encouraging people to use means of public transport instead of private cars. However, that requires the fulfillment of demands that present, as well as potential, passengers have. One of the most important passengers' demands is safety of all operations of public transport. In case of tram transport one aspect of safety is associated with the process of boarding the tram and alighting from it at stops separated from tram tracks by roadway, which forces passengers to enter the road. It is hazardous for all passengers and poses an additional risk for disabled passengers. In this paper an analysis of interactions between tram passengers and drivers of road vehicles at such tram stops, during the boarding and alighting from the tram was performed. For that purpose also a classification of tram stops stations was conducted, with the number of traffic lanes that passengers have to pass through being the main criterion. Also, the review of literature on this subject was conducted. For the research during the pilot study the tram network in Metropolis GZM in southern Poland was chosen and all tram stops stations on the network were inspected in order to obtain characteristics necessary for classification. Research during this pilot study allowed to identify conflict interactions that take place at tram stops. Examples of such interactions have been presented in the paper. Paper also contains conclusions and propositions of changes that may be implemented at tram stops that may lead to increase of the level of safety of passengers who try to board the tram or alight from the tram.

KEYWORDS: traffic safety; public transport; public transport stops; tram stops; tram transport safety

\section{INTRODUCTION}

Transport activity has become an inseparable element of life in modern urban areas. Development of means of transport makes travelling safer, faster and more comfortable. People are travelling more often and the set of potential trip purposes and destinations is expanding. However, it leads to numerous problems associated with transport activity, especially in large urban areas, where the number of cars is bigger in comparison with rural areas.

The examples of negative impact of transport on the environment may be classified into a few categories. One of the most commonly discussed areas of adverse influence of transport is pollution. Although most often pollution is equated with air pollution, one has also to mention the pollution of soil or water (Licbinsky \& Adamec, 2011). Another area of the negative influence is the noise emission. According to (Adamec, Licbinsky \& Cholava, 2011) it may be one of the most serious factors of negative impact on human's health, associated with transport. Transport activity in urban or metropolitan areas leads also to the problem of congestion, which causes time and energy wastes and imposes additional costs (Rao $\&$ Rao, 2012). Traffic incidents are another area of negative impact of transport. Most countries take different measures in order to reduce the level of risk in transport, nevertheless, the level of safety is still not satisfactory (Żochowska \& Soczówka, 2017). In Poland, there were c.a. 800 traffic incidents every year since 2012 reported to the police, that occurred near or on tramways. It includes around 100 accidents involving pedestrians every year, although that number has been declining (134 in 2015, 92 in 2017 and 72 in 2019). When it comes to accidents at or in the vicinity of public transport stops, their number is also not on a satisfactory level and its tendency is not unidirectional. In 2015 there was 147 such accidents, in 
2017 - 127, however in 2018 the number raised to 152 , only to drop again in 2019 (128 accidents). Every year there are fatalities among pedestrians in accidents at public transport stops (SEWIK Webpage, 2020). Moreover, Poland is a country with one of the highest values of the index of fatalities per 100,000 inhabitants - i.e. twice higher than Great Britain (KRBRD Webpage, 2016).

Increasing the role of public transport may be a solution to these problems. Public transport offers a set of benefits, i.e. it is able to transport large number of passengers (van Oort, van der Bijl \& Verhoof, 2017) which may lead to a smaller number of cars in cities. The growth of the significance of public transport is one of the most important goals of sustainable mobility.

From all sub-systems of public transport, tram transport is the one that stands out and offers additional benefits. Trams do not emit pollutants or fumes due to electric engines. They are able to transport even larger numbers of passengers than buses ("The Benefits of Light Rail”, 2010, p.2). Trams may be also characterized by high levels of energy efficiency (Glavas \& Ivanovic, 2013). Also, tramways with a right of way (usually separated from road traffic) may offer shorter travel times, especially in congested areas, and therefore tram transport (with other systems of railway transport such as light rail) may constitute a backbone of public transport in urban areas (Boquet, 2017). One may also argue that trams improve the general image of the area.

In order to encourage people to use means of public transport instead of individual transport it is indispensable to fulfill passenger's demands and requirements. In literature there are different approaches to passenger's demands. In (Walker, 2012, p. 24) author presented seven demands. One of them is the following: "public transport respects me in the level of safety, comfort and amenity it provides". In (Starowicz, 2007) a different set of demands was proposed, however "safety" is also one of them. Author also presented the ranking of passenger's demands and "safety" was classified higher that i.e. "cost", "comfort" or "accessibility". It proves that studies focused on safety of operations of public transport (and also tram transport - as a subsystem of public transport) are worth conducting because safety does have an influence on the choice of mode that travellers make.

This paper summarizes the pilot study of the interactions between tram passengers and road vehi- cles at tram stops. It contains a review of literature on the subject of safety at tram stops as well as in their vicinity and a proposition of classification of tram stop stations. The paper also presents results of the pilot study - selected cases of conflict interactions between tram passengers and road vehicles that were observed. It concludes with recommendations for improvements.

\section{LITERATURE REVIEW}

Sharing of space by tram and road transport may cause several issues, associated with i.e. infrastructure capacity (Nguyen-Phuoc, Currie, Young, \& De Gruyter, 2016), ("Managing traffic congestion", 2013), speed of road vehicles (Sobota, Żochowska, Szczepański, \& Gołda, 2018) or traffic control and organization in terms of priority of vehicles (Kaczmarek, \& Rychlewski, 2006), (Sermpis, Papadakos, $\&$ Fousekis, 2012). Beside these problems the aspect of traffic safety is also one of the most crucial. Any incident on a tram network is potentially dangerous as it exposes a large number of people at risk of injury, it decreases the level of passenger's trust in public transport's reliability and - due to smaller possibilities of detours on a tram network - causes significant disruptions. Therefore, the subject of tram transport safety has been taken up by many researchers, who investigated different aspects of this matter. Usually, however, tram safety is associated with a risk of incidents involving trams and road vehicles, whereas safety in the vicinity of tram stops is also of great significance for passengers.

The issue of interactions between pedestrians and vehicles is well covered in literature (Thakur \& Biswas, 2019), (Gorrini, Crociani, Vizzari, \& Bandini, 2018), (Liu, Zeng, Chen, \& Wu, 2017). Nevertheless, such studies are usually not associated with tram transport. In the study (Castanier, Paran \& Delhomme, 2012) authors proved that road users have little awareness of risk of accidents with trams, which may lead to a false perception of safety. In a paper (Olszewski, Osińska, \& Zielińska, 2016) authors state that the highest risk of a fatal incident involving pedestrians occurs when they have to cross tram tracks. Authors of the paper (Kruszyna \& Rychlews$\mathrm{ki}, 2013$ ) studied the influence of approaching tram on pedestrians' behavior on signalized crosswalks. Another study (Guerrieri, 2018) contains a classification of tramways in terms of the infrastructure and 
other identified features and characteristics that are related to safety of tram transport. Also, an identification of risks depending on the location of tramway and roadway was conducted, with examples. Authors of subsequent paper (Kahloche \& Chalib, 2017) provided a classification of incidents in railway systems, distinguishing four categories: user accidents, system accidents, user / system accidents and environment / system accidents. They also presented examples of each category and presented a method for the risk assessment in railway systems that includes five steps. In a study (Szmagliński, Grulkowski \& Birr, 2018) authors presented entities that are associated with risk management in tram transport. They also identified nine factors that pose hazard in tram traffic (Szmagliński et al., 2018, p. 3). Authors also performed an analysis of incidents that occurred in Gdańsk from 2013 to 2017 in order to identify hazardous locations on the tram network in that city. Another paper (Budzyński, Tubis \& Jamroz, 2019) also contains a method for the assessment of overall risk and a case study analysis for Gdańsk.

Indubitably, a significant aspect of safety of tram system is the safety at or in the vicinity of tram stops. That may include also safety of passengers during boarding the tram and alighting from the tram. In a few papers authors take that subject into account. In a paper (Tubis, Rydlewski \& Budzyński, 2019) authors proposed a method of the assessment of tram stops and they state that tram stops that are separated from tram tracks by roadway are dangerous because they require passengers to enter the roadway in order to board the tram. Authors of different study (Currie \& Smith, 2005) point out that such design of a tram stop also impedes the accessibility for disabled people and is perceived as hazardous by passengers. In the report ("Operations and safety of tramways in interactions with public space”, 2015) the issue of safety at tram stops was also discussed and different examples of configuration of tram stop, roadway and tram tacks have been presented. Author of the paper (Dyrkacz, 2019) points out that alignment of tram tracks next to the station (so there is no need to enter the roadway) is a factor that influences the level of tram transport safety.

However, none of the studies presented above provided a detailed analysis of interactions between tram passengers and drivers of road vehicles during boarding the tram and alighting from the tram at the tram stops that require passengers to enter the roadway.

\section{METHODOLOGY}

\subsection{General assumptions}

Basing on the conclusions from literature review, it appears that there is a lack of research on the interactions and behaviors of both tram passengers and drivers of road vehicles during the process of boarding the tram and alighting from the tram. Although such interactions do not include trams, they constitute a significant aspect of safety at tram stops. Any event when passenger has to enter the roadway should be perceived as dangerous, but different types of tram stops may pose different risk - and therefore may require different strategy in order to reduce the risk. Hence, the research was designed to study this problem. The study consists of two stages:

- first stage: pilot study,

- second stage: full study.

The pilot study was conducted and its goals included:

- inspection of existing tram stop stations in the area of analysis in order to obtain characteristics necessary for classification,

- the classification of trams stop stations in aspect of safety,

- identification of conflict interactions between passengers and drivers of road vehicles during boarding and alighting from the vehicle at chosen stop stations.

The research during pilot study was limited and the main purpose was the identification of the most important aspects of the issue.

During the pilot study, the observation of conflicts was performed by observers on chosen stop stations. The selection was performed basing on the classification, presented in chapter 3.2. Observers noted each conflict interaction that occurred during the boarding process in a detailed way, and recorded selected interactions using video device. Observers made the decisions to choose the interactions to record basing on the frequency of their occurrence. The observations were performed on weekdays, during rush-hours (in the morning and in the afternoon), for several hours.

Authors plan to expand this research in the second stage, when the full study will be conducted, by i.e. performing observation on a larger number 
of tram stop stations and for a longer time, recording each conflict interaction with a camera installed above the ground and performing a full statistical analysis of obtained results.

In order to clarify the nomenclature, it was assumed that each tram stop consists of at least one tram stop station. Stop station should be understood as a space designated for passengers to wait for the tram to arrive, to start the process of boarding the tram and to finish the process of alighting from the tram. It may be a platform or a part of the sidewalk.

Such division had to be introduced because each passenger uses only one station at a given time, therefore an analysis of interactions between tram passengers and drivers of road vehicles has to be performed for each station separately and not for a whole stop. Often one tram stop consists of stop stations that have different characteristics that influence such interactions, i.e. because of different number of traffic lanes to pass through. An example of tram stop with two stop stations has been presented in fig. 1 .

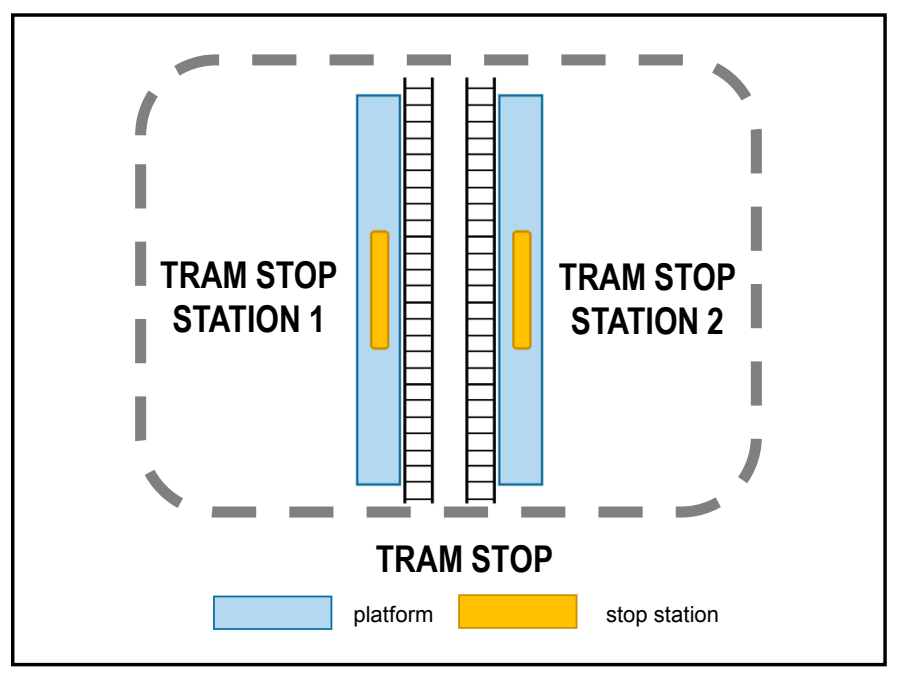

Figure 1. Tram stop stations at a tram stop. Source: Own research

\subsection{Classification of stop stations}

The main criterion for classification was selected on the basis of distinctive characteristic of tram transport - the fact that tram movement is constrained by the rails. That means, the tram - as opposed to bus transport, cannot deflect its trajectory in order to arrive at stop station as close to the curb as possible. Therefore, depending on the location of the stop station in relation to the roadway and the tram tracks, tram passengers who want to board the tram or alight from it may be required to pass through a certain number of traffic lanes designated for road vehicles. Hence, as the main criterion the number of traffic lanes that passengers have to pass through was chosen.

It was also assumed that each stop station may be classified into only one category. Also, category of a given stop station on a certain tram stop has no influence on categories of other stop stations at that tram stop.

It is possible to determine other criteria of classification, such as presence of safety devices, direction of traffic on traffic lanes on the roadway, traffic intensity (both road and tram traffic) or geometrical features of the station. Nevertheless, it was assumed that for the purposes of pilot study only one criterion shall be used.

Basing on the main criterion of classification, three categories of tram stop stations have been distinguished, as presented in fig. 2.

In case of the first category there are no traffic lanes between the stop station and the tram tracks. That means, passengers during boarding and alighting are not obligated to enter the roadway. The second category contains cases of stop stations where there is one traffic lane between the stop station and the tram tracks. Subsequently, stop stations separated from the tram tracks by two or more traffic lanes have been assigned to the third category.

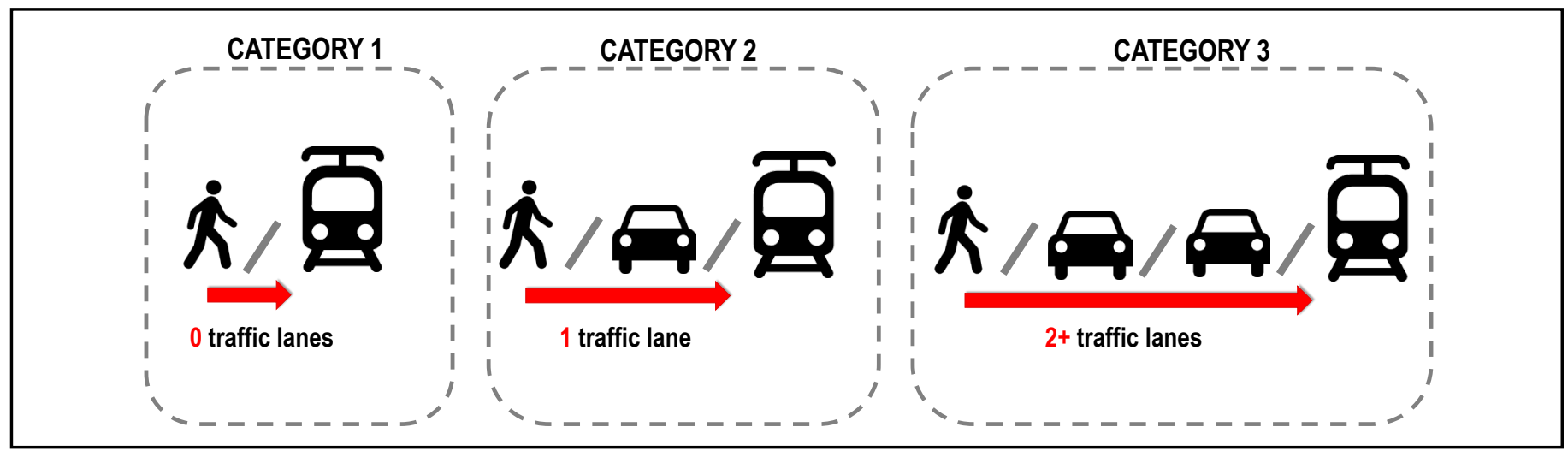

Figure 2. Categories of tram stop stations.

Source: Own research 


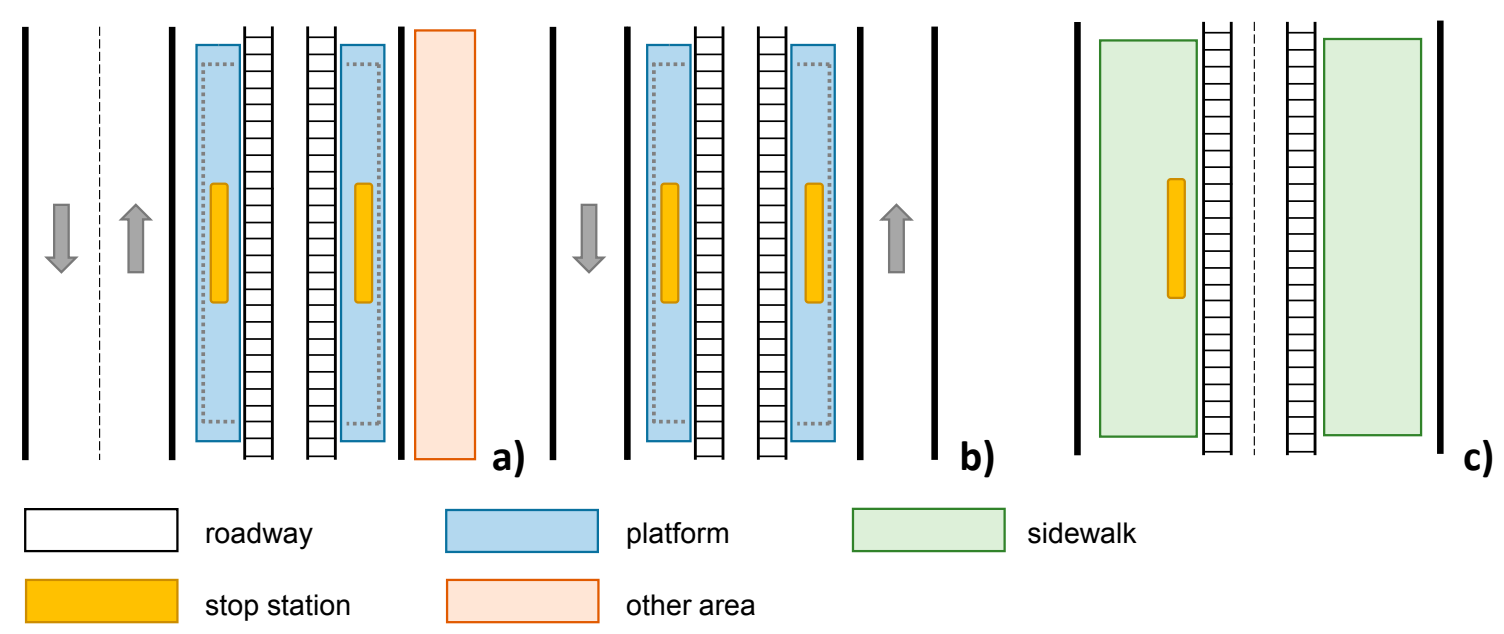

Figure 3. Examples of stop stations in case of category one. Source: Own research

It is possible to create various designs of stop stations from categories 1,2 and 3. At this stage of the study it was important to represent only the most important features of stop stations and less attention was paid to details of each stop station, in order to provide a general image of examples of stop stations from each category. Examples of stop stations from each category have been presented in fig. 3 to fig. 6 .

As regards the first category, it is possible that tram stop station is located on a platform, separated from road traffic (Fig. 3a and Fig. 3b) or on a sidewalk (Fig. 3c). In both cases, tram tracks are located directly next to the curb, so passengers can go directly from the stop station into the vehicle.

As presented in fig. 3, platforms may be located next to the roadway (fig. 3a) or between two one-way roadways (fig. 3b). Stop stations assigned to the first category provide the highest level of safety for passengers during boarding the tram and alighting from the tram.

In case of the second category there is one traffic lane separating the stop station from the tram tracks. An example of such stop station has been presented in fig. 4.

As presented in fig. 4. the stop station is located on the sidewalk, and tram tracks are located in the middle of the roadway. That forces passengers, who try to board the tram or alight from it, to enter the roadway and pass through one traffic lane. This design of stop stations provides lower level of safety than in case of stop stations assigned to the first category, however level of safety is higher than at stop stations from the third category.

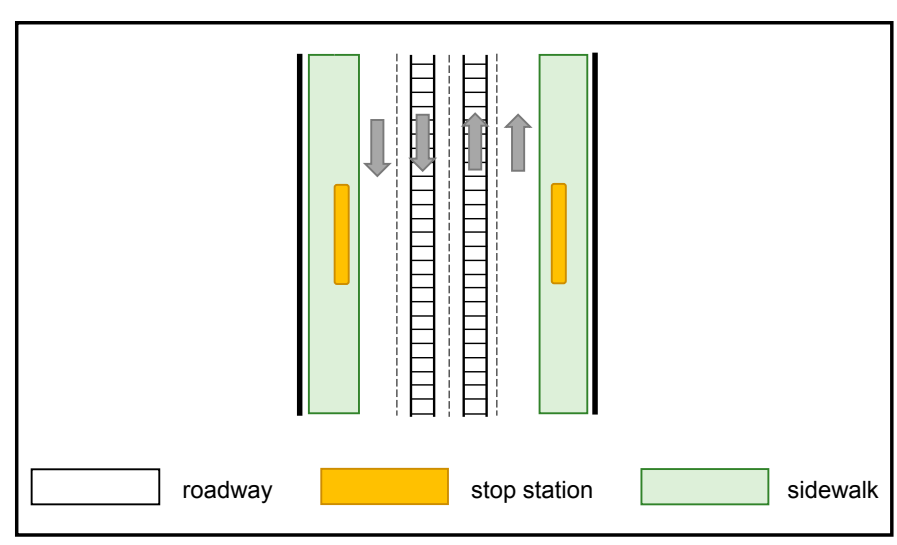

Figure 4. Example of stop stations in case of category two. Source: Own research

Examples of stop stations assigned to the third category have been presented in fig. 5 and fig. 6 . This category contains stop stations that are separated from tram tracks by two or more traffic lanes. It is particularly dangerous design of tram stop station for passengers as they have to pass through at least two traffic lanes in order to board the tram or to reach the stop station if they alight from the tram. Additionally, different directions of road traffic on the traffic lanes are possible. Passengers may be obligated to pass through traffic lanes that serve the same direction of road traffic or through traffic lanes that serve opposite directions of road traffic. Hence, passengers who try to board the tram or alight from the tram may have to pay attention to both sides of the roadway or to just one. It causes additional hassle, especially if passengers are unfamiliar with the traffic organization on the roadway.

The third category also contains examples of stop stations separated from the tram tracks by two or 
more traffic lanes and additional obstacles, such as a bus bay, which elongates the distance that has to be passed through in order to board the tram.

In fig. 5. two examples of stop stations separated by two traffic lanes from the tram tracks have been presented.

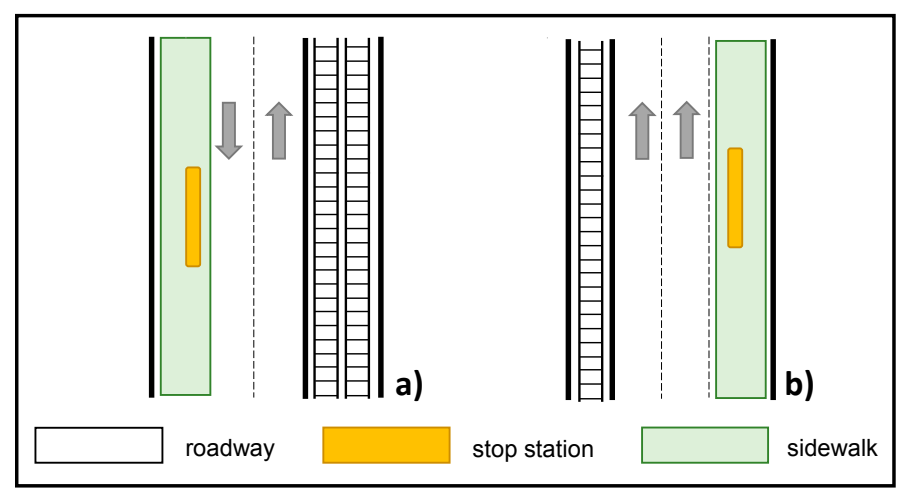

Figure 5. Examples of stop stations separated by two traffic lanes in case of category three.

Source: Own research

The two designs of tram stop station presented in fig. $5 a$ and fig. $5 b$ differ from each other in terms of direction of road traffic on traffic lanes on the roadway. In case of the fig. 5a passengers who try to board the tram have to pass through two traffic lanes which serve opposite directions of road traffic, whereas in case of the fig. $5 b$ the direction of road traffic is the same on both traffic lanes. In both cases there may be different interactions between tram passengers and road vehicles.

In fig. 6 other examples of stop stations from the third category have been presented.

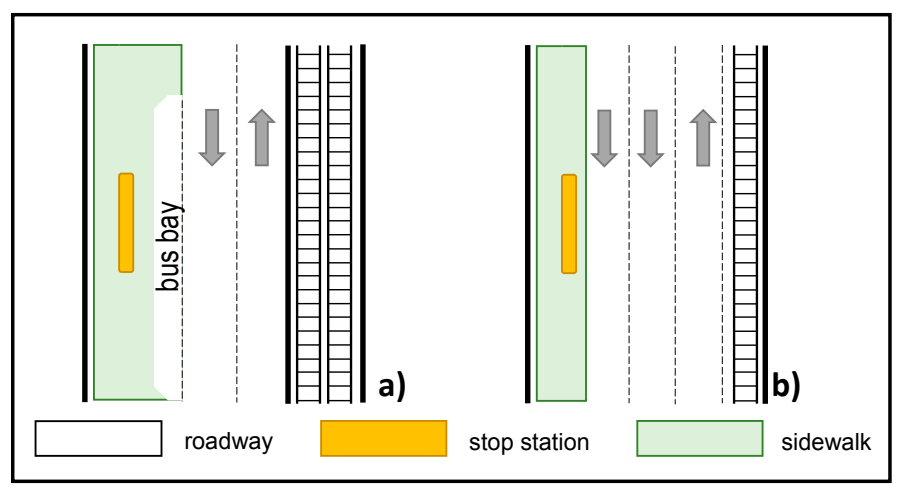

Figure 6. Examples of stop stations separated by two traffic lanes and a bus bay (a) three traffic lanes (b), in case of category three.

Source: Own research

Fig. 6a presents a stop station separated by two traffic lanes, serving opposite directions of road traffic and also a bus bay, which is a design ever more burdensome for tram passengers. In the best scenario, when there is no bus in the bus bay when the tram arrives, the distance that passengers have to pass through is only elongated. However, in rare instances when bus and tram arrive simultaneously additional threats occur. Bus may reduce visibility for passengers who want to board the tram and also makes them less visible for the drivers of road vehicles. It is possible that passengers who want to board the tram will be forced to enter the bus bay, walk in front of the bus and then wait on the edge of the bus bay until they may enter the roadway. On the other hand, for passengers who alight from the tram, bus standing in a bus bay may be an obstacle on their way to the stop station. They may be forced to choose a longer path from tram to the stop station (i.e. in front of the bus or behind the bus). That forces them to spend longer time on the roadway which is always an unwanted situation. Last but not least, such design is cumbersome for the road vehicle drivers as they have to pay attention to passengers who alight from the tram, passengers who want to enter the roadway from the stop station (they may be partially covered by the bus) and the bus itself.

Fig. $6 \mathrm{~b}$ presents a stop station separated from the tram tracks by three traffic lanes. This design is particularly dangerous, because the distance that has to be travelled is the longest and passengers have to pay attention to vehicles coming from both directions on three traffic lanes.

\section{THE AREA OF ANALYSIS}

Metropolis GZM was chosen as an area of analysis. It is a large metropolitan area in southern Poland which consists of 41 municipalities, that are highly diversified in terms of population, area or population density (Soczówka, Kłos, Szyndler \& Surlej, 2019). It is located in central part of Silesian Voivodship. The Metropolis contains cities such as Katowice (c.a. 300000 inhabitants), Sosnowiec (c.a. 200000 inhabitants) or Gliwice (c.a. 180000 inhabitants) as well as small municipalities, such as Kobiór (c.a. 5000 inhabitants) or Chełm Śląski (c.a. 6000 inhabitants). Total number of inhabitants in the Metropolis exceeds 2,3 million.

The area of the Metropolis has been presented in fig. 7 . 


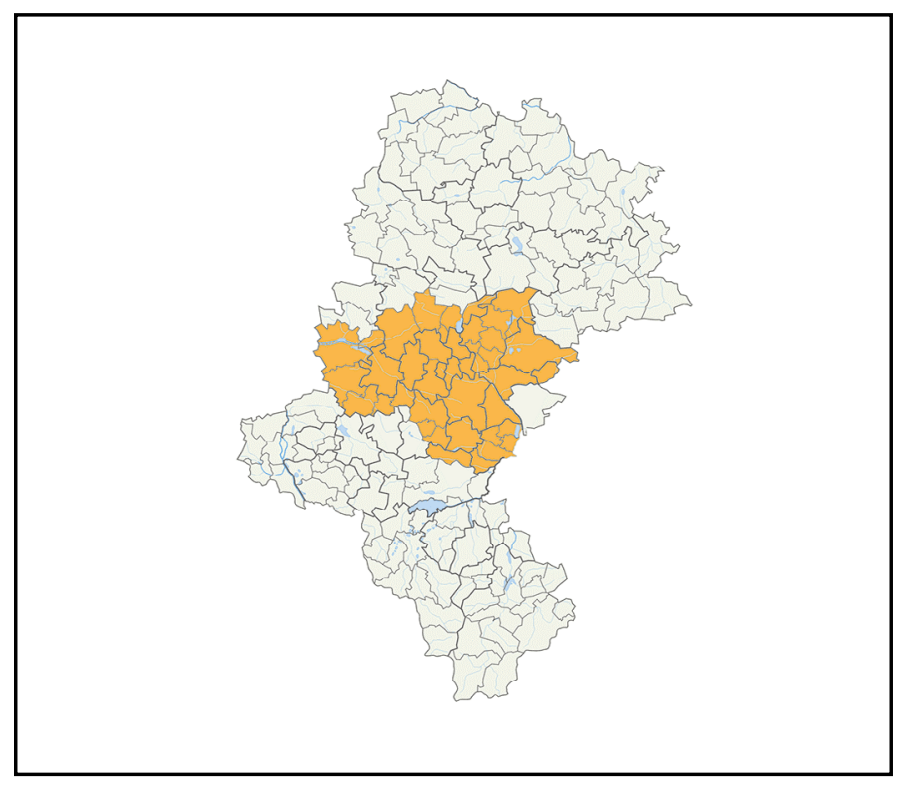

Figure 7. Metropolis GZM, distinguished from the area of Silesian Voivodship.

Source: www.metropoliagzm.pl

One of the biggest tram networks in Poland is located within the boundaries of the analysed metropolitan area. Total length of the network is $338 \mathrm{~km}$ (Silesian Trams Webpage, 2019). Most of the network consists of two-track lines, however there are still one-track segments in operation. The tram network is located in 13 of 41 municipalities, that constitute Metropolis GZM. The analysed tram network has been presented in fig. 8 .

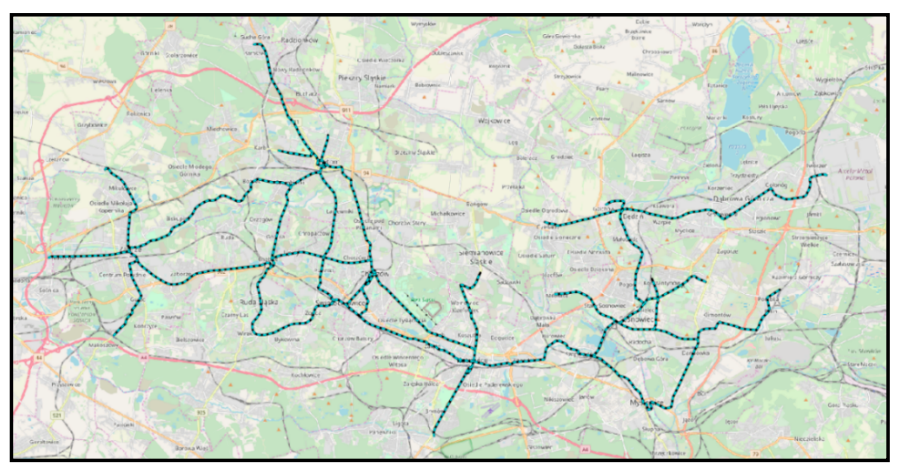

Figure 8. Tram network in Metropolis GZM.

Source: Own research, based on openstreetmap.org

First stage of the pilot study was an inspection of all existing tram stop stations located on the network. However, due to renovation works, some stop stations were closed and thus were removed from the analysis. In total, 307 tram stops were inspected, consisting of 610 stop stations.

Characteristics that were inspected included:
- location of stop station in relation to the roadway and the tram tracks,

- number of traffic lanes that passengers have to pass through between the stop station and the tram tracks,

- direction of road traffic at identified traffic lanes.

Identified characteristics allowed to perform a classification of analysed tram stop stations in the area of analysis.

In fig. 9 a percentage share of each category of stop stations in the area of analysis has been presented.

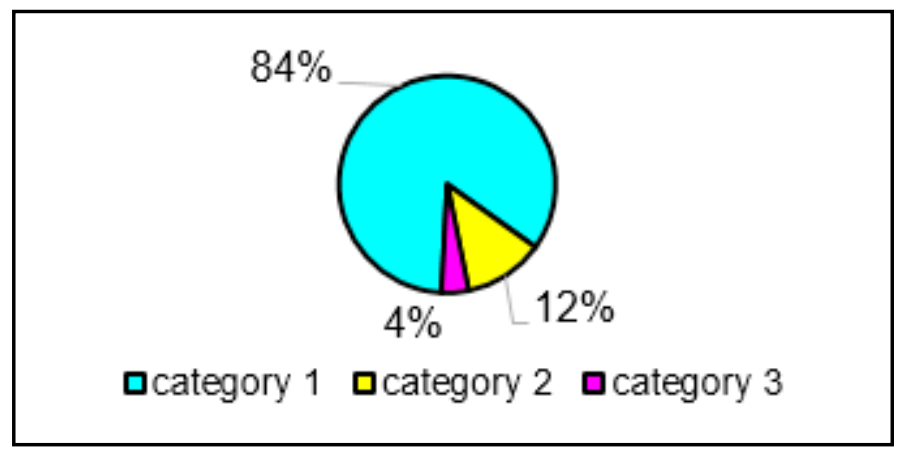

Figure 9. A percentage share of categories of stop stations in Metropolis GZM.

Source: $O w n$ research

According to fig. 9 most tram stop stations in Metropolis GZM (in operation during the pilot study) have been assigned to the first category (84\%). $12 \%$ of all stop stations are those separated by one traffic lane. The third category, in case of Metropolis GZM, contains $4 \%$ of all stop stations. Although this percentage value does not seem to be high, it is important to remember that due to large number of all tram stops, it is still more than 20 stop stations with the most dangerous design for passengers.

\section{RESULTS OF PILOT STUDY}

\subsection{General remarks and description of chosen location}

The main goal of the pilot study was the identification of conflict interactions between tram passengers and road vehicles. It was assumed, that further research will be focused on increasing the number of observations and therefore any numerical data will be presented after the completion of the further stages of the study. 
For purposes of this paper five cases of conflicts identified at one chosen tram stop station have been selected for presentation:

- case 1: passengers entering the roadway while road vehicles on one traffic lane are still in motion,

- case 2: passengers running to the tram on a last moment,

- case 3: early motion of road vehicles,

- case 4: passengers running to the tram from behind road vehicles,

- case 5: passengers entering the roadway between cars.

The chosen location was a stop station assigned to the third category, and separated from the tram tracks by two traffic lanes; each lane serving different direction of road traffic. It is the stop station located in Ruda Śląska. The design of the analysed stop station has been presented in fig. 10 .

\subsection{Case 1 - passengers entering the roadway while road vehicles on one traffic lane are still in motion}

The graphic representation of the first case of conflict interactions has been presented in fig. 11 . In this case passengers wait on the edge of the sidewalk for the tram to arrive. Once the tram arrives, they look for an acceptable gap in the stream of vehicles on the lane nearest to them (lane 1 in fig. 11) and then they enter the roadway. However, in this manner they force vehicles on the opposite lane (lane 2 in fig. 11) to stop. During the pilot study situations were observed in which the passengers already entered the roadway, and the vehicles on lane 2 were still moving. Therefore, passengers and vehicles are both on the roadway, in motion, at the same time. It increases the threat that drivers of road vehicles on lane 1 or lane 2 may not notice passengers early enough. Another important aspect that is associated with the analysed conflict interaction is the process of alighting from the tram - passengers have to make sure that road vehicles on lane 2 came to a complete stop before they can step out of the tram. It may be especially onerous for disabled passengers.

\subsection{Case 2 - passengers running to the tram on a last moment}

The graphic representation of the second case of conflict interactions has been presented in fig. 12 .

The second conflict interaction consists of two phases. In the first phase passengers board the tram and alight from the tram and road vehicles on traffic lanes 1 and 2 do not move. The second phase begins when the roadway becomes empty and road vehicles start their motion. However, the tram is still in the same position on the station, with the door open. It was observed that in some cases additional passengers run from the sidewalk onto the roadway, trying to board the tram at the last moment. They force the road vehicles to stop suddenly which causes two types of risk:

- additional passengers on the roadway may not be noticed early enough by drivers, which may lead to a collision between passengers and vehicles,

- sudden stop of a vehicle increases the probability of a rear-end collision between two vehicles.

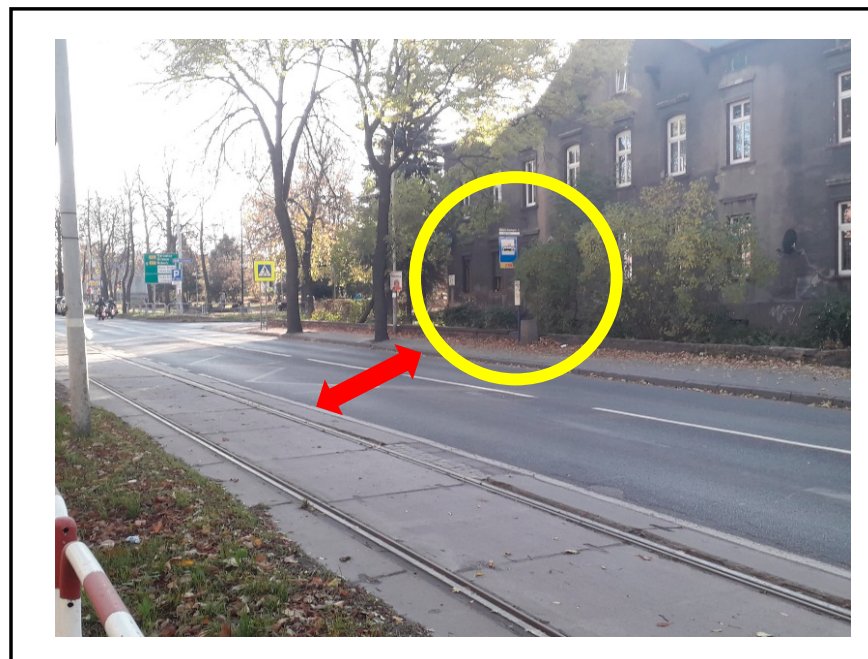

The stop station has been denoted with a yellow circle. It is located on the sidewalk. It is worth noticing, that the post with the traffic sign is partially covered by leaves, which makes it more difficult to notice for drivers. Red arrow shows the distance between the stop station and the tram tracks that passengers boarding the tram and alighting from it have to pass through (2 traffic lanes, c.a. 5,5 m). 


\subsection{Case 3 - early motion of road vehicles}

The third conflict interaction observed during pilot study has been presented in fig. 13 .

The third case of conflict interactions encompasses all situations when road vehicles start moving too early. In fig. 13 a case when vehicle on lane 1 starts too early has been presented, although early motion of vehicles on lane 2 would be also assigned to this general type of conflict interaction.

As presented in fig. 13 passengers enter the roadway and vehicles on both lanes do not move. When lane 1 becomes empty the vehicles on said lane start moving. Such behavior may cause several threats for passengers, because:

- it hinders the possibility of entering the roadway for any additional passengers who may be waiting on the sidewalk,

- it impedes the process of alighting from the tram, as passengers who step out of the tram become trapped on lane 2, between moving vehicles on lane 1 and tram tracks,

- it may cause road vehicles on lane 2 to start moving (drivers may think that moving

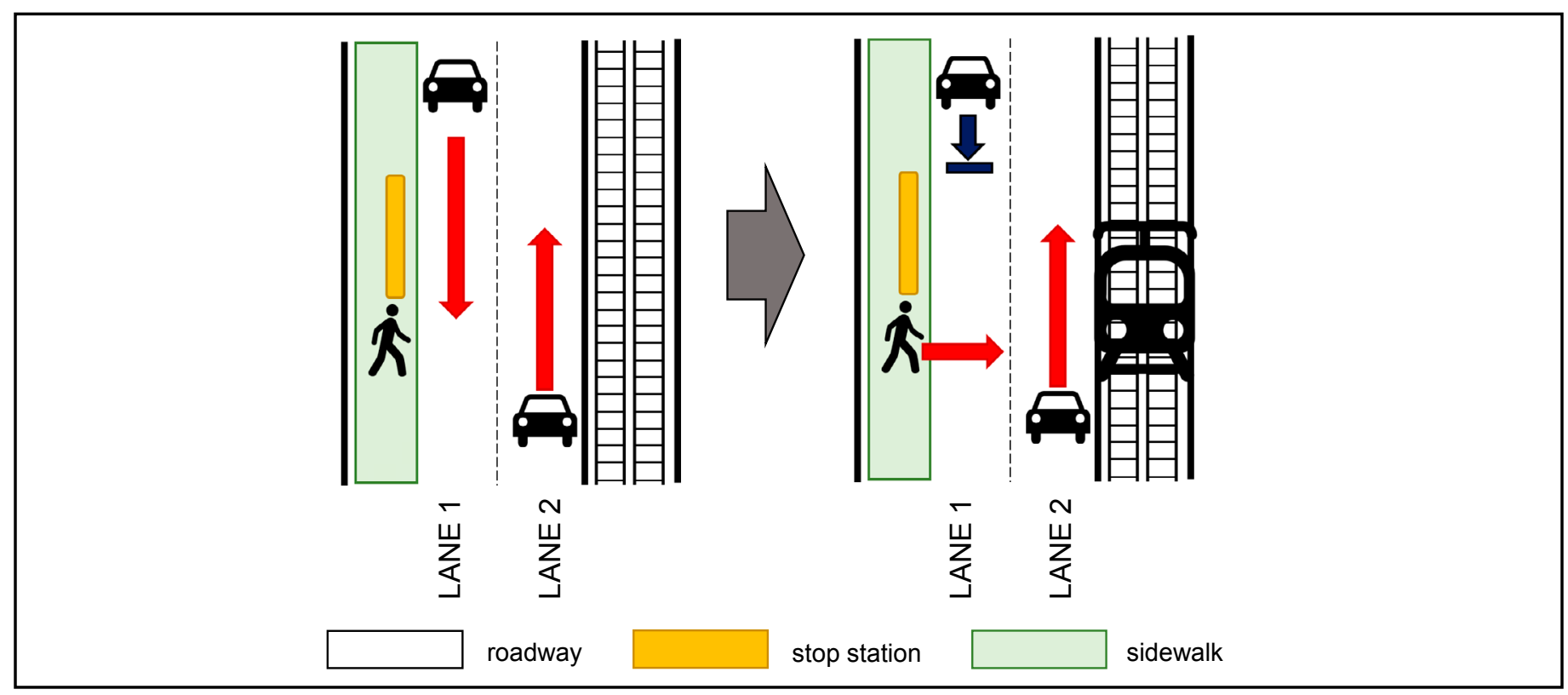

Figure 11. The first case of conflict interaction between tram passengers and road vehicles.

Source: Own research

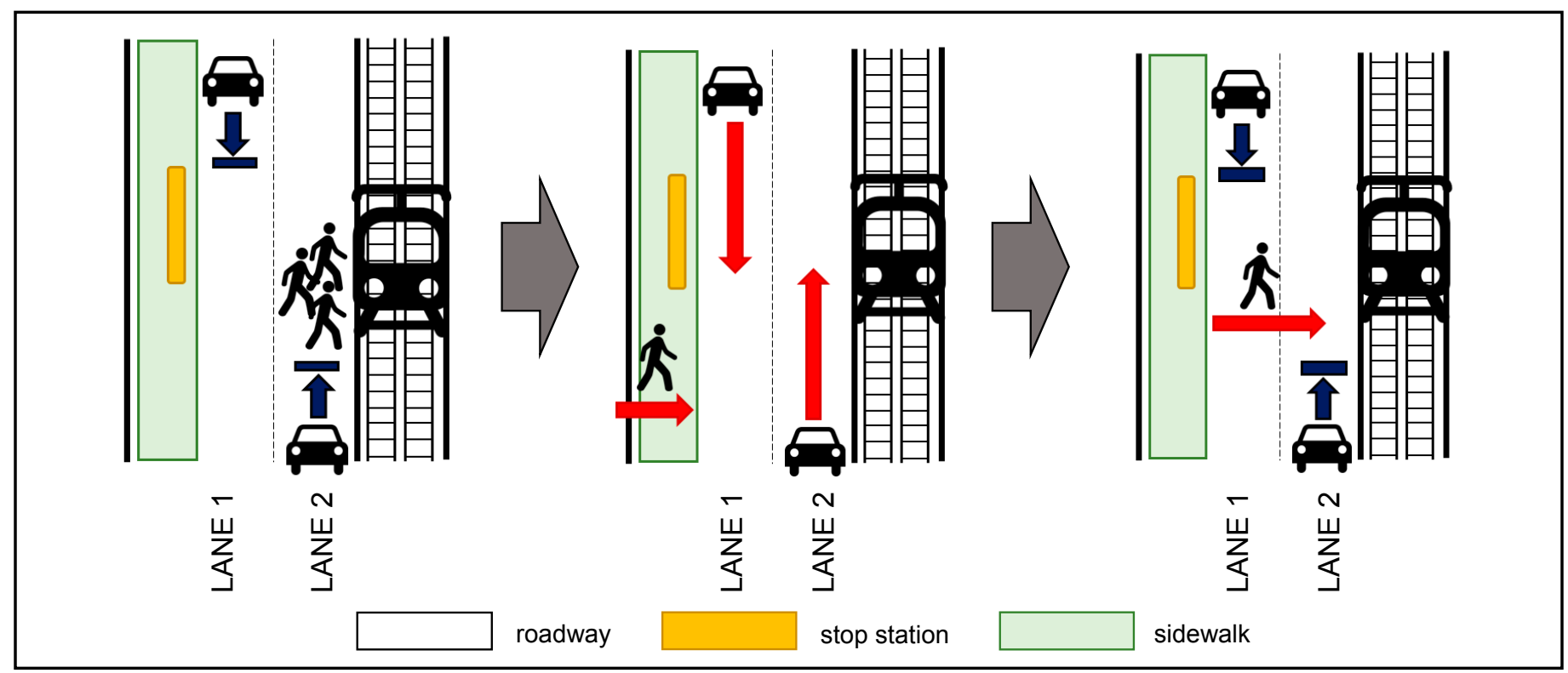

Figure 12. The second case of conflict interaction between tram passengers and road vehicles.

Source: Own research 
vehicle on the other lane means that roadway has become empty).

\subsection{Case 4 - passengers running to the tram from behind road vehicles}

The graphic representation of the fourth case of conflict interactions has been presented in fig. 14 .

In this case, the conflict interaction is caused by a risky behavior of the tram passenger. As presented in fig. 14, this type of conflict occurs when passenger tries to run to the tram from behind the vehicles.
Drivers usually pay attention to events that take place in front of the car, they observe passengers boarding and alighting from the tram, waiting for conditions that allow them to start moving. It is much more likely, that drivers will not be able to notice additional passengers if they run from behind the car.

\subsection{Case 5 - passengers entering the roadway between cars}

The fifth conflict interaction that was observed during pilot study has been presented in fig. 15 .

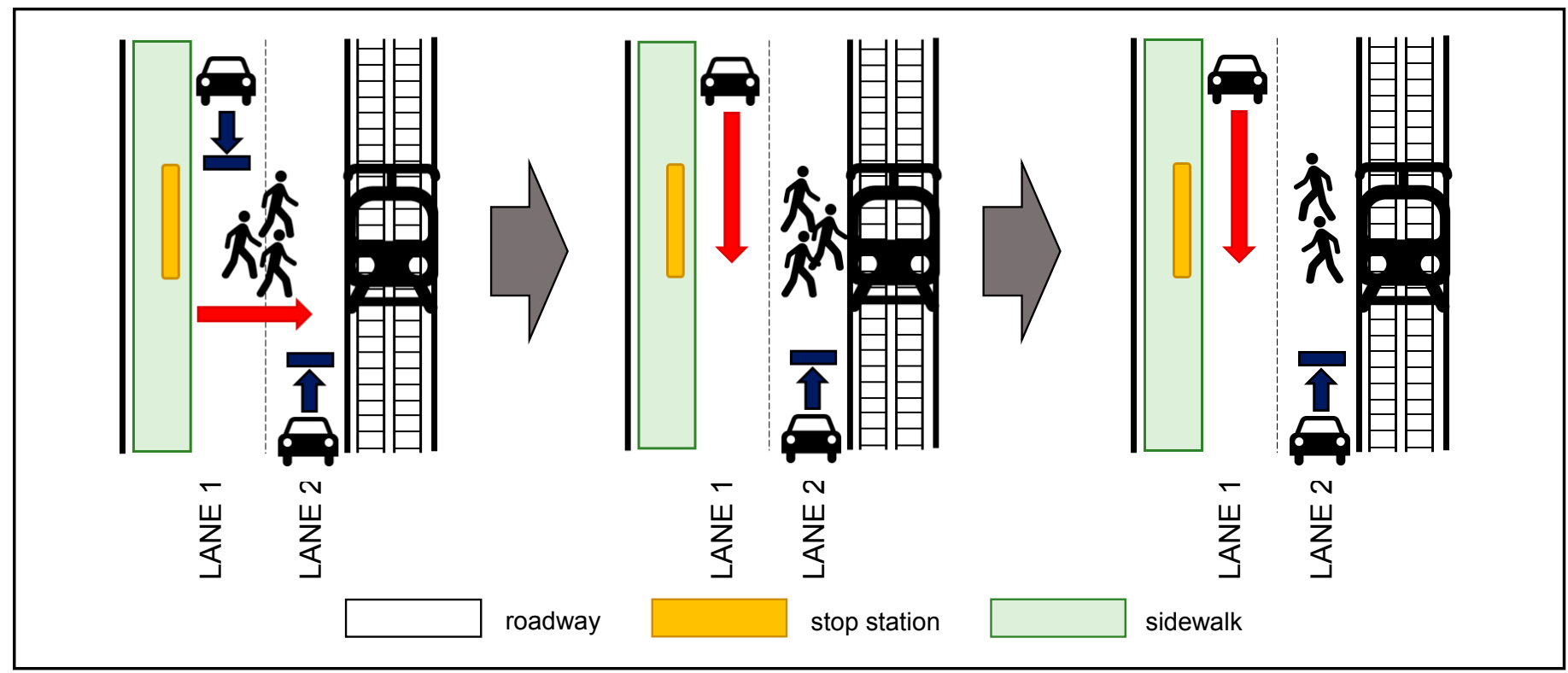

Figure 13. The third case of conflict interaction between tram passengers and road vehicles.

Source: Own research

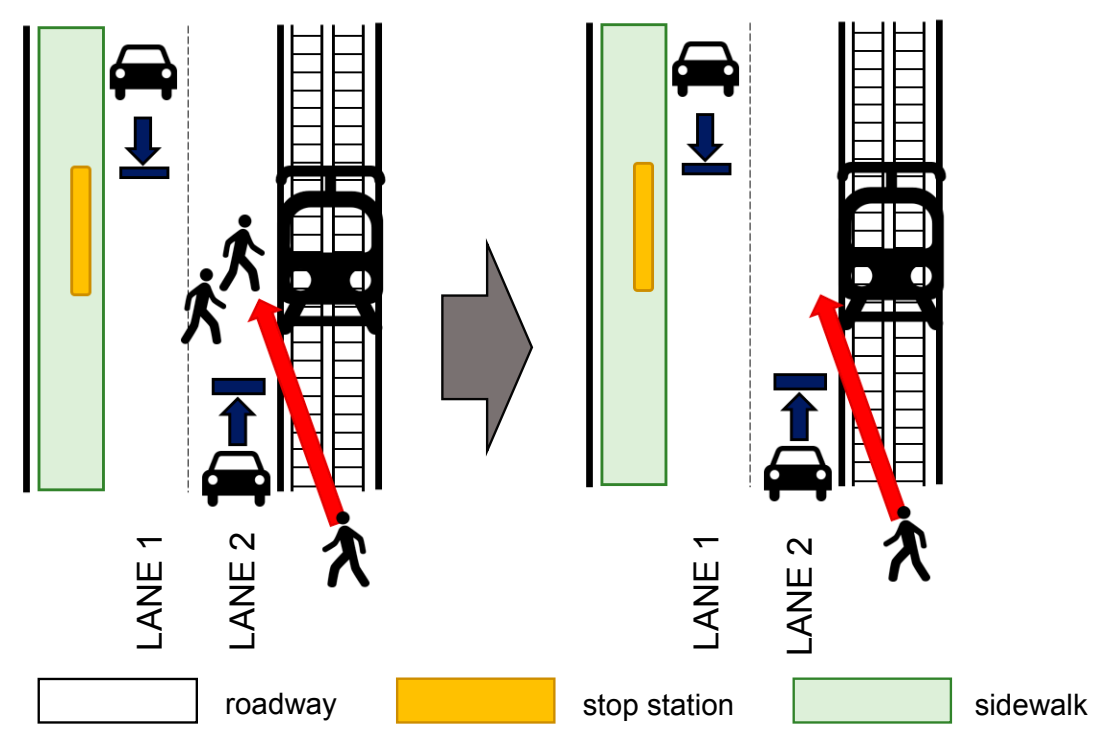

Figure 14. The fourth case of conflict interaction between tram passengers and road vehicles.

Source: Own research 


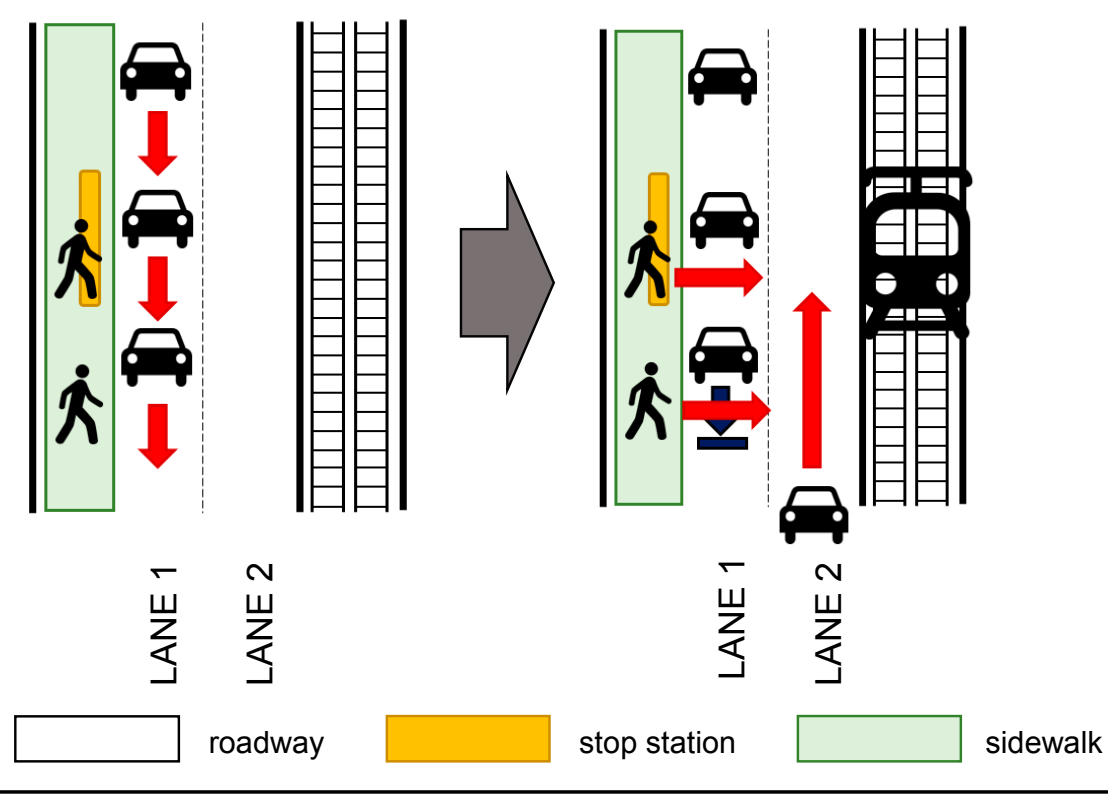

Figure 15. The fifth example of conflict interaction between tram passengers and road vehicles. Source: Own research

The fifth case pertains to the situation when a queue of cars forms on lane 1 whereas traffic on lane 2 is still moving. When the tram arrives, passengers who try to board the tram have to enter the roadway between the cars, becoming less visible for drivers on lane 2. The queue of cars also hinders the process of alighting from the tram, because passengers who step out of the tram onto the roadway have to adjust their path in order to bypass the cars. It may prove to be especially difficult for disabled passengers.

\section{RECOMMENDATIONS AND CONCLUSIONS}

The article contains the classification of tram stop stations, with the number of traffic lanes that passengers have to pass through in order to board the tram or alight from the tram being the main criterion of classification. Also, the results of the pilot study of interactions between tram passengers and road vehicles at stop stations with the most dangerous design have been presented.

It is possible to suggest a few general recommendations that may positively contribute to increase of the level of safety at tram stop stations assigned to third category. These recommendations may be classified into four groups.

The first group contains solutions associated with infrastructure. One solution may be a change of location of a stop station. Although it may prove to be the most effective it also may be the most difficult to introduce. Change of location of the stop station may influence the ridership and it is also important to take the location of neighboring stop stations into account. Another solution associated with the infrastructure may be a use of the easy-access stops. They may force road vehicles to reduce speed and facilitate the processes of boarding the tram and alighting from the tram for passengers.

The second group of solutions pertains to rail vehicles and their design. It is possible to use double-ended trams, so it would not be necessary to serve stop stations from the third category anymore. Boarding and alighting would be performed for both directions on stop stations closest to the curb (usually if one stop station at a given tram stop is assigned to the third category, the other one is a curb-side stop station). That solution, however, requires investments in the rolling-stock.

The third group of possible solutions is associated with traffic organization. Deployment of traffic lights before stop station may give a clear signal for drivers that they have to stop, and then passengers would be able to enter the roadway much safer.

The fourth group of potential solutions includes all actions associated with awareness raising campaigns for drivers and passengers. It is possible to provide both groups of road users with information on possible hazards on tram stops assigned to categories two and three. It could be also possible to deploy dedicated signs for drivers before tram stop stations, in order to remind them that the approach a special 
area, and that passengers may enter the roadway, if tram is present at the stop stations. However, the design of such signs must be in accordance with the traffic law regulations.

After completion of the second stage of the study, all sets of possible solutions will be expanded, taking into account specific aspects of each group of tram stop stations.

The pilot study allowed to identify conflict interactions between passengers and road vehicles that take place in the vicinity of a tram stop and laid the foundation for future research in this subject. However, it appears that there is a necessity of applying multi-criteria methods (i.e. for classification of stop stations), as such approach is well-founded in transport research (Jacyna \& Wasiak, 2015), (Sendek-Matysiak, 2019), (Nosal Hoy, Solecka, \& Szarata, 2019). It may also allow to perform more comprehensive analysis of such interactions. In the second stage of the research authors plan to apply much more systematic and complex way of analyzing traffic conflicts as well. Another area of possible expansion of the research is conducting separate analysis for specific groups of users of public transport stops (disabled people, elderly people, children), as members of these groups often have to rely on public transport due to lack of other possibilities and they are especially vulnerable to conflicts at public transport stops. Such research my contribute to enhancing the level of safety of trams stops as it is of great significance to make tram stops safe objects for both passengers and drivers.

\section{REFERENCES}

Adamec, V., Licbinsky, R., \& Cholava, R. (2011). Transport and health risks of transport. Transactions on Transport Sciences, 4 (3), 1-20. DOI: 10.2478/v10158-011-0011-y

Boquet, Y. (2017). The renaissance of tramways and urban redevelopment in France. Miscellanea Geographica - Regional Studies on Development, 21 (1), 5-18. DOI: 10.1515/ mgrsd-2017-0005

Budzyński, M., Tubis A., \& Jamroz, K. (2019). Identifying selected tram transport risks. IOP Conference Series: Materials Science and Engineering, 603, 1-10. doi:10.1088/1757899X/603/4/042053

Castanier, C., Paran, F., \& Delhomme, P. (2012). Risk of crashing with a tram: Perceptions of pedestrians, cyclists and motorists. Transportation Research Part F, 15, 387 - 394. DOI. org/10.1016/j.trf.2012.03.001

Currie, G., \& Smith, P. (2005). An innovative design for safe and accessible light rail/tram stops suitable for mixed traffic with median track operations. $28^{\text {th }}$ Australasian Transport Research Forum.

Dyrkacz, G. (2019). Bezpieczeństwo pasażerów w komunikacji tramwajowej w Krakowie. Transport Miejski i Regionalny, 6, 27-31.

Gorrini, A., Crociani, L., Vizzari, G., \& Bandini, S. (2018). Observation results on pedestrian-vehicle interactions at nonsignalized intersections toward simulation. Transportation Research Part F: Traffic Psychology and Behaviour, 59, 269-285. doi.org/10.1016/j.trf.2018.09.016

Glavas, H., \& Ivanovic, M. (2013). Energy efficiency of tram transport in the city of Osijek. International Journal of Electrical and Computer Engineering Systems, 4 (2), 39-43.

Guerrieri, M. (2018). Tramways in urban areas: An overview on safety at road intersections. Urban Rail Transit 4 (4), 223-233. https://doi.org/10.1007/s40864-018-0093-5

Jacyna, M., \& Wasiak, M. (2015). Multicriteria Decision Support in Designing Transport Systems. Tools of Transport Telematics. TST 2015. Communications in Computer and Information Science, 531. doi.org/10.1007/978-3-319-24577-5_2

Kaczmarek, M., \& Rychlewski, J. (2006). Tram priority traffic control on complex intersections. IFAC Proceedings Volumes 39 (12), 416-420. doi.org/10.3182/20060829-3-NL-2908.00072

Kahlouche, A., \& Chaib, R. (2017). An overview of Constantine's tram safety. Transport and Telecommunication, 18 (4), 324-331. DOI 10.1515/ttj-2017-0030

KRBRD. (2016). Bezpieczeństwo na drogach UE, najnowsze dane statystyczne. Retrieved from: https://www.krbrd.gov.pl/ pl/aktualnosci/bezpieczenstwo-na-drogach-ue-najnowszedane-statystyczne.html

Kruszyna, M., \& Rychlewski, J. (2013). Influence of approaching tram on behaviour of pedestrians in signalised crosswalks in Poland. Accident Analysis \& Prevention, 55, 185-191. doi. org/10.1016/j.aap.2013.03.015

Licbinsky, R., \& Adamec, V. (2011). The unfavorable influence of transport on the environment. Transactions on Transport Sciences, 4 (2), 1-22. DOI: 10.2478/v10158-011-0010-z

Liu, M., Zeng, W., Chen, P., \& Wu, X. (2017). A microscopic simulation model for pedestrian-pedestrian and pedestrianvehicle interactions at crosswalks. PLoS ONE, 12 (7), doi. org/10.1371/journal.pone.0180992

Managing traffic congestion. (2013). Victorian Auditor-General's Report.

Nguyen-Phuoc, D.Q., Currie, G., Young, W., \& De Gruyter, C. (2016). Modelling the direct impact of tram operations on traffic. $23^{\text {rd }}$ ITS World Congress, Melbourne, Australia, 10-14 October, 2016.

Nosal Hoy, K., Solecka, K., \& Szarata, A. (2019). The application of the multiple criteria decision aid to assess transport poliby measures focusing on innovation. Sustainability, 11 (5), 1-23, doi:10.3390/su11051472

Olszewski, P., Osińska, B., \& Zielińska, A. (2016). Pedestrian safety at traffic signals in Warsaw. Transportation Research Procedia, 14, 1174-1182. doi: 10.1016/j.trpro.2016.05.188 
Operations and safety of tramways in interaction with public space. Analysis and outcomes detailed report. (2015). European Cooperation in Science and Technology.

Rao, A.M., \& Rao, K.R. (2012). Measuring urban traffic congestion - a review. International Journal for Traffic and Transport Engineering, 2 (4), 286-305. DOI: h_p://dx.doi.org/10.7708/ ij_e.2012.2(4).01

Sendek-Matysiak, E. (2019). Multi-criteria analysis and expert assessment of vehicles with different drive types regarding their functionality and environmental impact. Scientific Journal of Silesian University of Technology. Series Transport, 102, 185-195. doi.org/10.20858/sjsutst.2019.102.15

Sermpis, D., Papadakos, P., \& Fousekis, K. (2012). Tram priority at signal controlled junctions. Proceedings of the Institution of Civil Engineers - Transport, 165 (2), 87-96. doi.org/10.1680/ tran.2012.165.2.87

\section{SEWIK. (2020). Retrieved from http://sewik.pl/search}

Silesian Trams. (2019). Tabor i infrastruktura. Retrieved from www.tram-silesia.pl/www/index.php/tabor/

Sobota, A., Żochowska, R., Szczepański, E., \& Gołda, P. (2018). The influence of tram tracks on car vehicle speed and noise emission at four-approach intersections located on multilane arteries in cities. Journal of Vibroengineering, 20 (6), 2453-2468. doi.org/10.21595/jve.2018.20087

Soczówka, P., Kłos, M., Szyndler, P., \& Surlej, Ł. (2019). Analiza bezpieczeństwa ruchu drogowego w latach 2013-2017 na obszarze Górnośląsko-Zagłębiowskiej Metropolii. Wspótczesne problemy transportu. Tom IV. Bezpieczeństwo Ruchu Drogowego. 47-60.

Starowicz, W. (2007). Jakość przewozów w miejskim transporcie zbiorowym. Kraków: Wydawnictwo Politechniki Krakowskiej.

Szmagliński, J.K., Grulkowski, S., \& Birr, K. (2018). Identification of safety hazards and their sources in tram transport. MATEC Web of Conferences, 231, 1-9. https://doi.org/10.1051/ matecconf/201823105008

Thakur, S., \& Biswas, S. (2019). Assessment of pedestrianvehicle interaction on urban roads: a critical review. Archives of Transport, 51 (3), 49-63. DOI: 10.5604/01.3001.0013.6162

TTF Transport Position Paper. The benefits of light rail. (2010). TTF Australia. Tourism \& Transport Forum.

Tubis, A., Rydlewski M., \& Budzyński M. (2019). Safety assessment of tram stops. Journal of KONBiN, 49 (2), 431-444. DOI 10.2478/jok-2019-0044

Van Oort, N., van der Bijl, R., \& Verhoof, F. (2017). The wider benefits of high quality public transport for cities. In Proceedings of the 2017 European Transport Conference in Barcelona, October 2017. 1-17.1

Walker, J. (2012). Human Transit. Washington: Island Press.

Żochowska, R., \& Soczówka, P. (2017). Method for identifying hazardous road locations at the intersection of tramlines and road traffic. Scientific Journal of Silesian University of Technology. Series Transport, 97, 201-213. DOI: https://doi. org/10.20858/sjsutst.2017.97.18. 